\title{
Journal of $K$-Theory
}

K-theory and its Applications in Algebra, Geometry, Analysis \& Topology
A. Bak
P. Balmer
S. J. Bloch
G. E. Carlsson
A. Connes

G. Cortiñas

E. Friedlander

M. Karoubi

A. Neeman

T. Porter

180 odor.

G. G. Kasparov

A. S. Merkurjev

J. Rosenberg

M. Schlichting

A. A. Suslin
V. Voevodsky
C. Weibel
G. Yu
G. Tang 


\section{Editorial Board}

Anthony Bak* (University of Bielefeld)

bak@math.uni-bielefeld.de

Paul Balmer (UCLA)

balmer@math.ucla.edu

Spencer Bloch (University of Chicago)

bloch@math.uchicago.edu

Gunnar Carlsson (Stanford University)

gunnar@math.stanford.edu

Alain Connes (IHES)

alain@connes.org

Guillermo Cortiñas (Universidad de Buenos Aires) gcorti@dm.uba.ar

Eric Friedlander (University of Southern California) efriedla@usc.edu

Max Karoubi (Institut de Mathématiques de Jussieu)

Max.karoubi@gmail.com

Gennadi Kasparov (Vanderbilt University)

Gennadi.kasparov@vanderbilt.edu

Alexander Merkurjev (UCLA)

merkurev@math.ucla.edu

Amnon Neeman (Australian National University)

neeman@maths.anu.edu.au
Tim Porter (Bangor University)

t.porter@bangor.ac.uk

Jonathan M. Rosenberg* (University of Maryland)

jmr@math.umd.edu

Marco Schlichting (University of Warwick)

m.schichting@warwick.ac.uk

Andrei Suslin (Northwestern University)

suslin@math.northwestern.edu

Guoping Tang (Graduate University of Chinese Academy of Sciences)

tanggp@gucas.ac.cn

Vladimir Voevodsky (Institute of Advanced Study)

Vladimir@ias.edu

Charles Weibel* (Rutgers, The State University of New Jersey) weibel@math.rutgers.edu

Guoliang Yu (Vanderbilt University)

Guoliang.yu@vanderbilt.edu

* Management Committee

Editorial Office Manager

Anthony Bak

Department of Mathematics

University of Bielefeld

33501 Bielefeld

GERMANY

bak@math.uni-bielefeld.de

Subscriptions: The Journal of K-Theory (ISSN 1865-2433) is published in six issues annually. Three issues form a volume and two volumes appear yearly. The subscription price for 2011 is $£ 658$ (\$1027 in USA, Canada and Mexico) which includes print and electronic access. The electronic-only access price for 2011 is $£ 588$ (\$924 in USA, Canada and Mexico). Single parts cost $£ 121$ (\$188 in USA, Canada and Mexico). Prices include delivery by air where appropriate. EU subscribers who are not registered for VAT should add VAT at their country's rate. VAT registered subscribers should provide their registration number.

Orders, which must be accompanied by payment should be sent to a subscription agent, book-seller, or direct to the publishers: Cambridge University Press, The Edinburgh Building, Shaftesbury Road, Cambridge CB2 8RU or, in the USA, Canada and Mexico, Cambridge University Press, Journals Fulfilment Department, 100 Brook Drive, West Nyack, New York 10994-2133. Japanese prices are available from Kinokuniya Company Ltd, PO Box 55, Chitose, Tokyo 156, Japan. Periodicals postage is paid at New York, NY and at additional mailing offices. POSTMASTER: send address changes in USA, Canada and Mexico to Journal of K-Theory, Cambridge University Press, Journals Fulfilment Department, 100 Brook Drive, West Nyack, New York 10994-2133.

This journal is included in the Cambridge Journals Online service. Further information, and online access for subscribers, is available at http://journals.cambridge.org/jkt

Copying: This journal is registered with the Copyright Clearance Centre, 222 Rosewood Drive, Danvers, MA 01923, USA. Organizations in the USA who are registered with the CCC may therefore copy material beyond the limits permitted by sections 107 and 108 of US copyright law subject to payment to CCC of the per-copy fee of $\$ 16.00$. This consent does not extend to multiple copying for promotional and commercial purposes. Code 1865-2433/2011 \$16.00.

Organizations authorized by the Copyright Licensing Agency may also copy material subject to the usual conditions. For all other use, permission should be sought from Cambridge or the American branch of Cambridge University Press.

Published by Independent Scholarly Online and Print Publishing

Printed in the United Kingdom at Bell \& Bain Ltd, Glasgow 